\title{
Ozonioterapia na prevenção e terapêutica da mastite em vacas leiteiras: Revisão de
}

\section{literatura}

\author{
Ozoniotherapy in the prevention and therapeutic of mastitis in dairy cows: Literature review \\ Ozonoterapia en la prevención y terapéutica de mastitis en vacas lecheras: Revisión de literatura
}

Recebido: 05/02/2021 | Revisado: 10/02/2021 | Aceito: 11/02/2021 | Publicado: 19/02/2021

Esther Abihail Fuentes Arévalo

ORCID: https://orcid.org/0000-0002-3489-0406

Universidade Federal de Alagoas, Brasil

E-mail: abihail.fuentes@gmail.com

Davi Francisco da Silva

ORCID: https://orcid.org/0000-0002-9518-8573

Universidade Federal de Alagoas, Brasil

E-mail: davifranciscodasilva01@gmail.com

Amanda Caroline Gomes Graboschii

ORCID: https://orcid.org/0000-0001-9711-8395

Universidade Federal de Alagoas, Brasil

E-mail: amandagraboschii@gmail.com

Juan Vitor Santos Brito

ORCID: https://orcid.org/0000-0002-9581-0465

Universidade Federal de Alagoas, Brasil

E-mail: juan.equi@hotmail.com

Pierre Barnabé Escodro

ORCID: https://orcid.org/0000-0002-9409-660X

Universidade Federal de Alagoas, Brasil

E-mail: pierre.escodro@propep.ufal.br

\begin{abstract}
Resumo
Este artigo é uma revisão da bibliografia realizada com o objetivo de compilar e analisar as informações existentes sobre a utilização do ozônio na prevenção e tratamento da mastite em vacas leiteiras, para assim conhecer os fundamentos da utilização do ozônio na pecuária e o potencial desse tratamento pode enfrentar a batalha contra a resistência microbiana que está se tornando mais forte nas últimas décadas. A metodologia utilizada foi a busca em diferentes bases de dados como Capes, Dialnet, Google Scholar, Scielo, LILACS, Spacenet, escolhendo artigos e documentos especificamente voltados ao uso do ozônio na agricultura e pecuária, bem como sua descoberta e desenvolvimento. A pesquisa resultou em uma riqueza de informações muito variadas sobre o uso do ozônio na pecuária, dando uma perspectiva de como a terapia com ozônio está sendo usada e seus possíveis usos futuros. Ao final desta revisão concluiu-se que embora seja verdade que existem muitas informações sobre o uso do ozônio na mastite em vacas leiteiras, mesmo a diversidade dessas informações não é abundante, limitando-se ao uso do ozônio na terapêutica e deixando um pouco de lado a prevenção, além disso, há também um déficit de informações sobre dosagens e formas de aplicação, portanto, sugere-se a criação de novas pesquisas que fortaleçam na prática as informações sobre esses pontos e reforcem as informações que já estão teoricamente disponíveis.
\end{abstract}

Palavras-chave: Ozônio; Células somáticas; Laticínios.

\begin{abstract}
This article is a review of bibliography carried out with the objective of compiling and analyzing existing information on the use of ozone in the prevention and therapy of mastitis in dairy cows, and thus to know the fundamentals of the use of ozone within livestock and the potential that this treatment may face the battle against microbial resistance that is currently growing stronger. The methodology used was by searching in different databases such as Capes, Dialnet, Google Scholar, Scielo, LILACS, Spacenet, choosing articles and documents specifically focused on the use of ozone in agriculture and livestock, as well as its discovery and development. The search resulted in a wealth of very varied information on the use of ozone in livestock, giving a perspective on how ozone therapy is being used and its possible future uses. At the end of this review it was concluded that although it is true there is much information on the use of ozone in mastitis in dairy cows, even the diversity of this information is not abundant, limiting itself to the use of ozone in therapeutics and leaving on a little side the prevention, in addition to this, there is also a deficit of information on dosages and means of application, so future research is suggested to strengthen information on these points and practically reinforce the information that is already theoretically available.
\end{abstract}

Keywords: Ozone; Somatic cells; Milk. 


\section{Resumen}

El presente artículo es una revisión de bibliografía realizada con el objetivo recopilar y analizar información existentente sobre el uso de ozono en la prevención y terapéutica de mastitis en vacas lecheras, y así conocer los fundamentos del uso de ozono dentro de la pecuaria y el potencial que este tratamiento pueda tener frente a la batalla contra la resistencia microbiana que se está fortaleciendo en la actualidad. La metodología usada fue mediante búsqueda en diferentes bases de datos como es Capes, Dialnet, Google Académico, Scielo, LILACS, Spacenet, escogiendo artículos y documentos enfocados específicamente de uso de ozono en agricultura y pecuaria, así como su descubrimiento y desarrollo. La busqueda dio como resultado un cúmulo de información muy variada sobre el uso de ozono en la pecuaria, dando una perspectiva de como esta siendo usada la ozonoterapia y sus osibles usos a futro. Al final de esta revisión se concluyó que si bien es cierto hay mucha información sobre el uso de ozono en la mastitis en vacas lecheras, aun la diversidad de esta información no es abundante, limitándose al uso de ozono en la terapéutica y dejando un poco de lado la prevención, además de esto, también existe un déficit de información sobre dosificaciones y medios de aplicación, por lo que se sugieren futuras investigaciones para fortalecer información sobre estos puntos y reforzar prácticamente la información que ya se posee teóricamente.

Palabras clave: Ozono; Células somáticas; Lecheria.

\section{Introdução}

O ozônio é um gás formado por três átomos de oxigênio, um gás que apresenta uma série de benefícios, curativos, preventivos e imunoestimuladores, devido às suas propriedades oxigenadoras, catalíticas e germicidas; capaz de agir contra bactérias, fungos e vírus. (Arichivala, et al., 2012; Zorrilla, 2001).

Nas áreas de produção animal, uma das fazendas com maior uso de antibióticos são as fazendas leiteiras dadas a alta taxa de mastite que ocorre. A mastite de vaca, juntamente com os distúrbios de fertilidade, é a causa mais importante da falta de rentabilidade de uma fazenda de gado leiteiro (Kleinschroth, et al., 1991). Um elemento fundamental para a não ocorrência de mastite é uma boa rotina de ordenha, que exige manobras apropriadas pelos ordenhadores, além de materiais de qualidade e efetivos diante do alto desafio que a produção de leite apresenta.

Segundo estudos, com o uso de tratamentos intramamários de ozônio, uma reação favorável foi alcançada em até $60 \%$ das vacas com mastite aguda, sendo totalmente excluído o uso de antibióticos nesse grupo. Além disso, diferentes estudos concordam que a terapia com ozônio é uma cura eficaz, rápida e barata contra a mastite clínica e subclínica, evitando os efeitos negativos do uso prolongado de antibióticos. (Ogata, et al., 2000).

Portanto, o uso do ozônio como tratamento na mastite, ofereceria um benefício extraordinário para a indústria; beneficiando-se das unidades produtoras (vacas), que não seriam mais expostas a um grande número de antibióticos, o que desencadeia uma resistência bacteriana; assim como agricultores, que não teriam mais gastos exorbitantes na compra de antibióticos; bem como a indústria de processamento de laticínios, que deixaria de ter problemas com o leite descartado devido à presença de antibióticos ou produziria produtos com prazo de validade curto devido ao grande número de células somáticas.

É assim que se faz necessária a criação de fundamentos teórico-práticos que gerem dados científicos que embasem o uso do ozônio nas propriedades leiteiras.

Dados que buscam avaliar o uso do ozônio em diferentes concentrações e veículos, no tratamento da mastite clínica e subclínica; por sua vez avaliando sua eficácia em relação aos antibióticos geralmente utilizados nesta área e assim, conhecer a eficácia tanto nos tratamentos quanto na qualidade do leite, avaliando sua composição para verificar se ele não sofre alterações devido ao uso do ozônio.

Nesse contexto, este artigo busca coletar e analisar informações existentes sobre o uso do ozônio na prevenção e tratamento da mastite em vacas leiteiras. A metodologia utilizada foi por meio de uma revisão bibliográfica realizada de forma qualitativa, descritiva e exploratória, realizada por meio da utilização de diferentes plataformas de bancos de dados como Capes, Dialnet, Google Academic, Scielo, LILACS, Spacenet, escolhendo artigos e documentos especificamente focalizados. utilização na agricultura e pecuária, bem como a sua descoberta e desenvolvimento (Pereira, et al. 2018). 


\section{Propriedades do Gás Ozônio}

O ozônio é uma variedade alotrópica de oxigênio, conhecida por sua presença na estratosfera, onde é formado pela ação dos raios ultravioleta do sol, que absorve em grande parte, evitando assim sua ação prejudicial sobre os seres vivos. O ozônio é um gás formado por três átomos de oxigênio; a combinação de uma molécula de oxigênio com um átomo de oxigênio levará à formação de ozônio. Esse gás foi descoberto pelo cientista Holándes van Marun em 1783 e investigado e aplicado pelo médico alemão Christian Friedrich Schonbëin em 1840. E foi na Primeira Guerra Mundial que ele teve seus usos terapêuticos (Campos, et al., 2003).

A geração de ozônio é alcançada através da passagem de oxigênio puro através de uma descarga elétrica de alta tensão e alta frequência. Essa reação química, realizada por uma equipe especial, produz um gás $(\mathrm{O} 3)$ com diferentes concentrações de ozônio.

O ozônio melhora o metabolismo de maneira integral, favorecendo a circulação sanguínea nos tecidos inflamados, fornecendo mais oxigênio e energia. Basicamente, a terapia com ozônio é baseada no uso do ozônio como catalisador (Carrijo, et al., 2006).

O ozônio tem um poder oxigenador maior que o do oxigênio normal e, portanto, melhora o processo respiratório no nível celular. A ação germicida direta do ozônio em todos os tipos de microorganismos, fungos, bactérias e vírus também é conhecida. (Sunnen, 2003)

O ozônio é instável e decompõe-se com alguma facilidade no oxigênio normal e no oxigênio nascente, que é um forte oxidante. Devido a essa característica, atua com grande eficiência como desinfetante e é constituído como o mais sério concorrente do cloro. É pouco solúvel em água e muito volátil. Ele fica na água por apenas alguns minutos; em sua aplicação, aproximadamente $10 \%$ são perdidos devido à volatilização. O ozônio é considerado o desinfetante microbicida mais eficiente e requer tempos de contato bastante curtos. Foi demonstrado que quando o ozônio é transferido para a água por um misturador em linha sem movimento, as bactérias são destruídas em dois segundos. Portanto, o tempo de contato na ozonização não é importante. (Bocci, 1993)

A velocidade com que o ozônio mata bactérias é muito maior que a do cloro, cerca de três mil vezes maior, porque, embora ambos sejam oxidantes, o mecanismo de ação é diferente.

O ozônio mata as bactérias através da quebra da membrana celular. Esse processo, conhecido como destruição das células pela lisina, produz a dispersão do citoplasma celular na água: lipídios insaturados são os principais componentes da membrana citoplasmática que as bactérias possuem, o ozônio ataca as ligações olefínicas. Essa ação inicia a destruição da capacidade de funcionamento da célula e pode até ser suficiente para causar a morte de células mais fracas. O ozônio tem um alto potencial para a oxidação é instável e exerce sua própria ação de desinfecção, atacando enzimas, grupos sulfidrila ou aldeídos, liberando compostos peróxidos, que também são desinfetantes, tudo isso leva à dispersão do citoplasma e consequentemente à morte do microorganismo (Ricaurte, 2006).

Em vez disso, o cloro deve ser introduzido através da parede celular da bactéria e espalhado no citoplasma, ação que depende em grande parte do tempo de contato. Por seu grande poder oxidante, o uso do ozônio pode ser recomendado nos prétratamentos. Tratamento de água para a redução de metais dissolvidos e a remoção de matéria orgânica, o que permite economia de coagulantes e tempos de retenção. Outra vantagem sobre o cloro é que ele não confere água, cor, cheiro ou sabor e evita outros aspectos toxicológicos da cloração (Mustafa, 1998).

O ozônio introduzido em qualquer ambiente executa certas ações fundamentais tais como: ação microbicida; efeito bactericida, efeito viricida, efeito esporicida, ação deodorante (Glaze, 1987; Ricaurte, 2006).

O ozônio em concentrações ligeiramente superiores às usadas no restante das bactérias é capaz de acabar com a resistência dos esporos. 


\section{Mastites na Pecuária Leiteira: uma Abordagem Através da One Health}

\subsection{O que é mastite?}

Mastite, ou inflamação da glândula mamária, é a doença mais comum e cara do gado leiteiro na maior parte do mundo. Além do estresse e das lesões físicas na glândula, as infecções por bactérias invasoras ou outros microorganismos (fungos e vírus) são as principais causas da mastite (Radinović, et al., 2019).

\subsection{Mastite clínica e subclínica}

Em casos de mastite clínica, o quarto infectado geralmente está inflamado, em algumas vacas fica dolorido ao toque, o leite está visivelmente alterado pela presença de coágulos, descamação ou descoloração do soro e às vezes sangue. Em casos mais graves (mastite aguda), a vaca mostra sinais generalizados: febre, pulso rápido, perda de apetite, redução aguda da produção de leite (Hughes, et al., 2018).

Em contraste, a mastite subclínica é sutil e mais difícil de corrigir. A vaca parece saudável, o úbere não mostra sinais de inflamação e o leite parece normal. Apesar disso, os microrganismos e as células brancas do leite (células somáticas) que combatem as infecções são encontrados em grande número no leite (Radinović, et al., 2019).

As perdas de leite e lucro devido à mastite clínica são óbvias, a produção de leite cai drasticamente e o leite de vacas tratadas com antibióticos deve ser descartado por três a quatro dias. Além disso, muito mais leite é perdido devido à mastite subclínica porque:

- A grande maioria dos casos é subclínica (em média, para cada caso clínico, existem 20 a 40 subclínicos);

- A redução da produção de leite devido à mastite subclínica tende a persistir por um longo período de tempo e afeta a produção de vacas infectadas.

O controle da mastite subclínica é mais importante do que o simples tratamento dos casos clínicos, pois:

- V V Vacas com casos subclínicos são reservatórios de organismos que levam a infecções de outras vacas;

- A maioria dos casos clínicos começa como subclínico; portanto, controlar os casos de mastite subclínica é a melhor forma de reduzir os casos clínicos.

O impacto da mastite também vai além das portas da fazenda, com o leite. Mudanças na composição do leite (redução de cálcio, fósforo, proteína e gordura e aumento de cloro e sódio) reduzem sua qualidade. Além disso, os antibióticos usados no tratamento da mastite são uma grande preocupação industrial e de saúde pública (Guimarães, et al., 2017). A presença de resíduos de antibióticos no leite interfere no processo de fabricação de muitos produtos lácteos (queijos e outros produtos fermentados). Sabores indesejáveis reduzem o valor dos laticínios e a presença de baixos níveis de antibióticos pode causar problemas de saúde aos consumidores (Calderón, et al., 2011). (Tabelas 1 e 2) 
Tabela 1. Efeito do CS na composição do leite.

\begin{tabular}{|c|c|c|}
\hline & Normal & Alto CCS \\
\hline Sólidos & 13.1 & 12.0 \\
\hline Lactose & 4.7 & 4.0 \\
\hline Gordura & 4.2 & 3.7 \\
\hline Proteína T & 3.6 & 3.6 \\
\hline Caseína & 2.8 & 2.3 \\
\hline
\end{tabular}

Fonte: Calderón, et al., (2011).

Tabela 2. Efeito das células somáticas na produção de queijo.

\begin{tabular}{|c|c|c|c|c|}
\hline & $\begin{array}{c}\text { Leite com CCS } \\
\text { normal }\end{array}$ & $\begin{array}{c}\text { Leite com CCS } \\
\text { alto }\end{array}$ & \\
\hline Leite (L) & Queijo (kg) & $\begin{array}{c}\text { Desempenho } \\
\text { real (\%) }\end{array}$ & Queijo (kg) & $\begin{array}{c}\text { Desempenho } \\
\text { real (\%) }\end{array}$ \\
\hline 5.0 & 0.503 & 10.06 & 0.498 & 9.76 \\
\hline 5.1 & 0.518 & 10.16 & 0.487 & 9.74 \\
\hline 5.0 & 0.509 & 10.18 & 0.504 & 9.69 \\
\hline 5.4 & 0.565 & 10.46 & 0.512 & 9.30 \\
\hline 5.3 & 0.538 & 10.15 & 0.483 & 9.66 \\
\hline & 10.20 & 10.20 & 0.497 & 9.63 \\
\hline
\end{tabular}

Fonte: Calderón, et al., (2011).

\subsection{Uso de antibióticos na perspectiva de One Health}

Produtos de origem animal são essenciais para a nutrição e segurança de milhares de pessoas em todo o mundo. A pecuária responde por $40 \%$ das receitas agrícolas gerada no mundo. Atualmente, está comprovado que a demanda por produtos de origem animal aumentará nos próximos anos, pois é necessário um manejo adequado e equilibrado para se obter produtos de boa qualidade e seguros para o consumo (Nabarro, et al., 2014).

Diante dessa realidade, os governos de todo o mundo devem procurar políticas públicas que incentivem e promovam a pecuária, incentivando ou trabalhando dois setores pobres e incentivando a produção familiar e, também, aumentando a economia rural, medidas que por sua vez devem ser amigas do ambiente. Gerando benefícios aos ecossistemas. (Ibid).

Por este motivo, deve ficar claro que se trata de uma abordagem de Saúde Única ou Saúde Única, a fim de evitar uma intensificação da produção pecuária prejudicial à saúde humana, cabelos que devem ser experimentados para reduzir os riscos à saúde, e que, incentivam convergência de múltiplos interesses em busca de um projeto comum: acabar promovendo a desnutrição sem agredir o ecossistema e a saúde humana ou animal. (Gochez, et al., 2019; Nabarro, et al., 2014).

Seguindo a atual abordagem One Heath, a Organização Mundial de Saúde Animal (OIE) também aposta no não controle e redução da resistência antimicrobiana, razão pela qual, nos últimos anos, foi encaminhada à fila de dados para 
estabelecer abusos de antibióticos, todas essas ações foram realizadas em parceria com a Organização Mundial da Saúde (OMS) e a Organização das Nações Unidas para a Alimentação e Agricultura (FAO). Esta é uma referência mundial para a situação e preocupação das organizações ligadas à saúde humana e animal, em relação ao uso indiscriminado de antibióticos e seu impacto na saúde mundial devido à resistência bacteriana. (Gochez, et al., 2019)

\section{Considerações de Uso da Ozonioterapia da Pecuária Leiteira}

\subsection{Ozônio nos sistemas agrícola e de produção de leite}

O ozônio tem uma grande variedade de aplicações na agricultura e, portanto, na pecuária também, um dos usos mais estabelecidos e usados é na desinfecção de água para irrigação.

A rega com sistemas de água ozonizada consiste basicamente em uma maior contribuição de oxigênio para a raiz, livre de vírus, bactérias, fungos, algas, esporos e qualquer outro microorganismo, de modo que o crescimento é muito mais rápido que o normal, com mais vivacidade e força, além de mais produtividade com as doenças do ozônio são controladas, uma vez que a maioria das doenças das plantas é causada por contágio. O ozônio destrói todos os microorganismos por ação direta na água e pela quantidade de oxigênio liberada (Özlem, et al., 2015). A irrigação ozonizada protege contra infecções; destrói até bactérias, vírus e cistos parasitários difíceis de combater por outros procedimentos que também envolvem o uso de produtos químicos, por vezes prejudiciais ao consumo humano e sempre ao meio ambiente. O produto irrigado com sistemas de água ozonizada (e armazenado e / ou transportado em ambientes ozonizados) mantém todas as suas características por muito mais tempo, em perfeitas condições de imunidade microbiológica (Beltran, et al., 2001).

Com o uso do ozônio, os benefícios são obtidos com uma colheita mais volumosa e uma colheita mais produtiva alcançada em um número menor de dias, já implica economia na quantidade de água de irrigação, mas, por outro lado, também é muito importante economizar custos com fertilizantes e outros aditivos. Lembre-se de que, por exemplo, o uso de fertilizantes é reduzido em até 50\% (Ibid).

Além disso, o efeito da água ozonizada consiste basicamente em uma maior contribuição de oxigênio para a raiz, a água ozonizada que atinge a irrigação é completamente livre de vírus, bactérias, fungos, algas, esporos e qualquer outro microorganismo. A ausência de germes fornece à água as melhores condições possíveis para alcançar um crescimento muito mais rápido do que o habitual. A planta crescerá mais vividamente, como pode ser verificada após um pequeno período de tempo (entre 30 a 40 dias desde o início do tratamento) e com mais vitalidade e força. Além de melhorar a aparência da planta (folhas, caules, raízes), mas também de seus frutos, eles cumprirão o ciclo de amadurecimento em menos tempo do que o habitual e, em geral, terão um tamanho uniforme, compacto e forte e volume relativamente maior (Ramirez, et al., 2012).

Todas as opções acima resultarão na coleta de mais quilos de produto com o mesmo esforço. Outra conseqüência notável é a que excede a qualidade do sabor dos produtos que conterão, devido ao efeito da irrigação por ozonização, uma maior quantidade de açúcare, favorecendo assim uma linha de produção de alimentos mais saudável e ecologicamente correta (Özlem, et al., 2015).

\subsubsection{A ozonização da água}

Em primeiro lugar, é um potente agente germicida capaz de eliminar bactérias, vírus e fungos, tudo isso sem causar a formação de compostos tóxicos ou deixar resíduos, uma vez que se decompõe espontaneamente em oxigênio, aspecto em que supera outros desinfetantes comumente usados para esses fins (Frisón, et al., 2013).

O estudo de um sistema para incorporar esse elemento na água utilizada na irrigação começou em 1993. A experiência desenvolvida consiste na instalação de um gerador de ozônio que injeta esse elemento na água através do próprio conduto de água. É necessário fazer uma modificação no sistema de conduítes e na instalação de um tanque. 
A contribuição do oxigênio chega à planta através da raiz que, finalmente, se constitui com mais força, dando à planta maior capacidade de alimentação, maior ancoragem ao solo e proteção total contra possíveis infecções (Ibid).

Por outro lado, o uso do sistema (ozônio adicionado à água de irrigação) excede na economia de fertilizantes, inseticidas e outros produtos químicos ou orgânicos, pois, com o uso do ozônio, não é necessário incorporar esse tipo de aditivo à irrigação. do que em sessões de rega alternativas. A experiência confirmou que o uso de fertilizantes pode ser reduzido em $50 \%$.

A mistura de ozônio e oxigênio é calculada com base na quantidade de metros cúbicos e no fluxo / hora a ser usado para irrigação.

\subsubsection{Principais efeitos da ozonificação de água potável}

A morte de bactérias e a inativação viral estão relacionadas à concentração de ozônio na água e à duração do contato com microorganismos. As bactérias são as mais rapidamente destruídas.

Os vírus são mais resistentes que as bactérias. Foi demonstrado que os polivírus dos tipos I, II e III são inativados pela exposição a concentrações de ozônio dissolvido de $0,4 \mathrm{mg} /$ litro por um período de contato de quatro minutos (Beltran, et al., 2001; Frisón, et al., 2013).

No caso de compostos de ferro, manganês e arsênico, a oxidação ocorre muito rapidamente, deixando compostos insolúveis que podem ser facilmente removidos por meio de um filtro de carvão ativado. Os íons sulfeto são oxidados em íons sulfato, uma substância inofensiva (Beltran, et al., 2001).

O ozônio é um agente muito poderoso no tratamento de materiais orgânicos. Os orgânicos são essencialmente naturais (ácidos umidificantes e fumicos) ou sintéticos (detergentes, pesticidas). Alguns orgânicos reagem com o ozônio muito rapidamente até a destruição, em minutos ou até segundos (fenol, ácido fórmico), enquanto outros reagem mais lentamente com o ozônio (ácidos umidificantes e húmicos, vários pesticidas, tricloretano etc.). Em alguns casos, os materiais orgânicos são parcialmente oxidados com ozônio. Uma grande vantagem da oxidação parcial de materiais orgânicos é que, quando parcialmente oxidados, os materiais orgânicos polarizam muito mais do que originalmente, produzindo materiais insolúveis complexos que podem ser removidos com filtros de carvão ativado (Ibid).

A turbidez da água é eliminada pela ozonização através de uma combinação de oxidação química e neutralização de carga, as partículas coloidais que causam turbidez são mantidas em suspensão por partículas de carga negativa que são neutralizadas pelo ozônio. O ozônio também destrói materiais coloidais através da oxidação de materiais orgânicos (Ibid).

A oxidação de matéria orgânica, metais pesados, sulfuretos e substâncias estranhas causa a supressão de sabores e odores estranhos que a água pode conter, proporcionando uma melhoria na qualidade e aparência da água, tornando-a mais adequada para consumo e gozo (Beltran, et al., 2001; Frisón, et al., 2013).

\subsection{Ozônio na produção de leite}

Atualmente, as altas concentrações de animais em regime intensivo ou estável e o sistema de construção das instalações geram uma alta concentração de emanações amoniacais e ácidas e um aumento na flora microbiana, que produz um ambiente irrespirável e livre de oxigênio, isso causa um alto número de doenças, principalmente doenças respiratórias, que reduzem o desempenho da fazenda de gado. Para corrigir essa situação, o agricultor utiliza apenas como medida a ventilação dos estábulos, ovelhas e currais, ao custo de um alto aumento no consumo de energia no aquecimento e, assim, não impede que germes e bactérias ainda existam no interior do navio (Ricaurte, 2006).

O ozônio, devido às suas propriedades bactericidas, oxidantes, desinfetantes e desodorizantes, pode transformar o ambiente interno dos edifícios dos animais, conseguindo: 
- Regenere o ar, aumentando sua oxigenação.

- Destrua bactérias, vírus, etc.

- Reduza muito os odores.

- Redução da ventilação e consequentemente dos custos de aquecimento no inverno.

- Redução de custos em medicamentos; dado que alguns dias após a instalação do gerador de ozônio, o próprio agricultor verá que os animais têm menos doenças, encontrando-se mais "lozanos" e aumentando o consumo de ração.

- Substituto de cloro, aplicando ozônio na água de abastecimento das fazendas de gado.

- Desinfecção e eliminação de odores de jangadas de chorume.

- Não será necessário "descansar" áreas ou gado por meses.

- A contribuição do ozônio em altas doses por vários dias será suficiente para deixar os navios completamente desinfetados e livres de qualquer tipo de doença.

Para essas propriedades, o ozônio é aplicado há mais de 30 anos em fazendas de criação de animais nos países do norte da Europa, EUA e no início da Colômbia, onde devido ao clima, a ventilação é necessária para reduzi-lo ao mínimo.

\subsection{Aplicações do ozônio na reprodução}

O ozônio, devido às suas propriedades oxidantes e de regeneração de oxigênio, é o elemento mais adequado para a criação de qualquer espécie animal, devido à sua ação viridicida, bactericida, fungicida e desodorizante em geral.

$\mathrm{Na}$ medicina humana, a ozonioterapia tem sido utilizada em diversas áreas e é considerada uma proposta para o tratamento terapêutico eficaz e seguro da endometriose. (Morais, et al., 2020)

Maior oxigenação dos ambientes reprodutivos e melhor equilíbrio nos animais, tanto pelo efeito iônico quanto pelo efeito bacteriostático e bacteriológico. Portanto, a ozonização do ar encontra aplicação para seus benefícios na criação de todos os tipos de animais e, em geral, em qualquer tipo de animal de criação intensiva e estável (Ricaurte, 2006).

Nestes casos, o ozônio tem dois objetivos principais:

- Esterilize o ambiente e mantenha-o livre de germes por sua ação bactericida e bacteriostática.

- Desodorize o ar contaminado.

O ozônio, em sua ação bactericida eminente, destrói quaisquer bactérias, vírus ou germes dele; do exterior ou do próprio ambiente, onde você encontra os meios mais adequados para o seu desenvolvimento devido à existência de emanações dos dejetos. Uma vez eliminados os elementos poluentes, em princípio, uma sobrecarga de ozônio permanece no ar, impedindo qualquer contaminação subsequente (ação bacteriostática) (Vidal, et al., 2009).

No fundo, a ação desodorizante aparece, as circunstâncias nas quais a criação industrial de animais é forçada a concentrar grandes quantidades de animais em locais relativamente pequenos ou estagnados, essas emanações que provêm de uma parte dos próprios animais e de outro animal. O detrito e as reações químicas que ocorrem no "leito" (gases amoniacais, sulfeto de hidrogênio, dióxido de carbono, etc.) tornam o ambiente viciado e inadequado para os próprios animais devido aos odores que se originam.

O ozônio, ao destruir todas essas substâncias orgânicas por oxidação, elimina esses odores, convertendo o ar viciado em ar adequado, onde os animais realizam digerências mais completas, com maior assimilação dos alimentos, obtendo uma conversão considerável ou aumento de processo de transformação de ração em carne, com sua consequente lucratividade (Beltran, et al., 2001; Frisón, et al., 2013).

\subsection{Aplicações clínicas da ozonioterapia em bovinos leiteiros}

De acordo com diferentes estudos e a adaptação do uso do ozônio à medicina veterinaia, foram feitos avanços no 
tratamento de diferentes doenças. O ozônio em doses adequadas, possui alto poder de ação: Oxidante - Bactericida - Germicida - Viricida - Fungicida. Destrói muito rapidamente estreptococos, estafilococos, colibacilos, etc., bem como as toxinas mais difundidas da difteria e do tétano. (Frisón, et al., 2013).

Algumas doenças ou patologias nas quais o ozônio é aplicado com sucesso

- Infeccioso: Bacteriano (estreptococos, estafilococos, colibacilos, laminite, infusão, etc.) Viral (Arterite Viral Equina, Encefalite Viral Equina, etc.) Parasitária, Fúngica (Infecções Vaginais e Cutâneas).

- Reumático: fibromialgia, osteoartrite, etc.

- Vascular periférico: arterial e venoso.

- Gastrointestinal: cólon espasmódico, hemorróidas, gastrite, colite, etc.

- Oftalmológico: neurite óptica, etc.

- Dermatológico: psoríase, dermatite seborréica, etc.

- Metabólico: Rabdomiólise, azotúria, etc.

- Traumatológico: tendinite, dor aguda e crônica.

- Oncológico: adjuvante de terapias oncológicas

- Cardiológico: cardiopatia isquêmica

(Vidal, et al., 2009).

Entre seus benefícios está a ampla variedade de vias de aplicação, sendo utilizadas as vias parenteral (IM, IV, SC), intra-articular, intra vaginal, intra-mamária, transretal e tópica (Vidal, et al., 2009).

Dentro das contra-indicações, temos as seguintes considerações:

- Não plicar via respiratoria pelo poder oxidativo.

- Pode ser usado em conjunto com tratamentos convencionais.

- Não forma hábito nem cria resistência a microorganismos.

- Não deixa resíduos ou subprodutos contaminantes, pois após o uso, o produto resultante é o oxigênio (O2) (Ibid).

Nesse sentido, e visto o amplo leque de vias de aplicação e benefícios, seu uso pode ser muito favorável no tratamento da mastite em bovinos leiteiros. Estudos feitos demostram que o uso de tratamentos intramamários de ozônio, apresentam uma reação favorável até do $60 \%$ das vacas com mastite aguda. Também, estudos concordam que a terapia com ozônio é uma cura eficaz, rápida e barata contra a mastite clínica e subclínica. (Ogata, et al, 2000).

Além do uso do ozônio na mastite, dada a sua ampla gama de uso, na pecuária leiteira poderia ser utilizado com grande segurança em áreas como pododermatite e tratamentos adjuvantes para aumento da imunidade, o que traria maiores benefícios para esta área de produção pecuária. (Ibid).

\section{Ozonioterapia no Tratamento e Prevenção de Mastite}

\subsection{Terapêutica de mastites em bovinos leiteiros}

A mastite é uma doença grave sofrida por animais produtores de leite, causando grandes perdas econômicas, devido à redução na produção de leite e ao seu baixo valor nutricional. A mastite é caracterizada pela ocorrência de alterações físicas, químicas e bacteriológicas no leite, incluindo alterações no tecido mamário (Philpot, et al., 2002; Ramírez, et al., 2012). A mastite afeta a qualidade do leite em termos de composição e produção (Kitchen 1981). As células somáticas são as principais células epiteliais que se desprenderam do revestimento glandular e dos glóbulos brancos (leucócitos) que penetram na glândula mamária em resposta a um dano ou infecção específica (Sharma 2007). As células do leite somático incluem $75 \%$ dos leucócitos, como neutrófilos, macrófagos, linfócitos e $25 \%$ das células epiteliais. Durante a inflamação (mastite), o maior aumento da SC é devido ao influxo de neutrófilos no leite para combater a infecção e tem uma estimativa de 90\% (Jones, et 
al.,1984; Harmon 1994; Sharma, et al., 2011). A relação mais precisa entre infecção intramamária e contagem de células somáticas (CCS) pode ser avaliada no nível de um quarto quando o CCS excede 200.000 células / $\mathrm{ml}$ (Schukken, et al., 2003). Além disso, o CCS em salas saudáveis é consistentemente baixo e geralmente abaixo de 200.000 células / ml (Hamann, 1990). Na mastite subclínica, os patógenos não causam destruição suficiente do tecido alveolar, de modo que ele se reflete nas características do leite, mas o CCS é aumentado indicando a infecção do leite (Harmon 1994).

A administração de antibióticos intramamários é o método mais comum usado no tratamento da mastite bovina. No entanto, atualmente, este tratamento está apresentando poucos resultados em termos de recuperação da infecção, principalmente devido ao mau manejo e ao desenvolvimento de resistência por patógenos (Sampimon, et al., 2011). O tratamento da mastite aguda de bovinos durante o período de amamentação representa uma das maiores perdas econômicas da produção pecuária. Isso está relacionado ao custo dos tratamentos (serviço veterinário e medicamentos), à diminuição da produção e ao preço de venda do leite, bem como ao aumento da contagem de células somáticas no volume da amostra de leite, aumento no número de vacas descartadas e aumento nas perdas devido à presença de resíduos de antibióticos no leite e na carne (Zadoks, et al., 2001; Pitkälä, et al., 2004; Swinkels, et al., 2005).

Uma série de sistemas de produção coexiste na América Latina, desde os mais tradicionais, nas mãos de camponeses em regiões isoladas, até grandes empresas modernas, integradas vertical e horizontalmente. A tecnologia exigida pelos vários sistemas é muito diferente e as MVZs devem estar muito conscientes do escopo e das limitações de cada método ou entrada que aplicam ou recomendam. O monitoramento da qualidade do produto tem uma ampla demanda social e também desempenha um papel estratégico na proteção do mercado interno e no acesso a mercados no exterior.

$\mathrm{O}$ mundo exige responder à crescente demanda por proteínas de origem animal, cuidar do meio ambiente e, ao mesmo tempo, combater doenças que afetam a pecuária e a saúde humana (FAO, 2010).

A presença de mastite é um problema muito sério para a pecuária leiteira e é uma das principais causas de perdas econômicas para o agricultor $\mathrm{e} / \mathrm{ou}$ produtor. As maiores perdas resultam da redução na produção de leite devido à mastite subclínica. A higiene em canetas e sala de ordenha é muito importante e todos sabem que quanto menor o nível de higiene, maior o risco de infecção.

Segundo estudos, com o uso de tratamentos intramamários de ozônio, uma reação favorável foi alcançada em até $60 \%$ das vacas com mastite aguda, sendo totalmente excluído o uso de antibióticos nesse grupo. Além disso, diferentes estudos concordam que a terapia com ozônio é uma cura eficaz, rápida e barata contra a mastite clínica e subclínica, evitando os efeitos negativos do uso prolongado de antibióticos. (Ogata, et al., 2000).

Portanto, o uso do ozônio como tratamento na mastite subclínica permitirá zero dias de retirada no leite, esterilizará perfeitamente a sala de bactérias, vírus e fungos, devido à sua potente ação oxidante, não permitirá o efeito de resistência dos microrganismos e terá a possibilidade de desfrutar de um leite livre de antibióticos, anti-inflamatório, com células somáticas moderadas e com maior qualidade protéica, tanto no leite quanto em derivados.

\subsection{Prevenção de mastites em bovinos leiteiros}

Nos últimos anos, à medida que os múltiplos benefícios do ozônio foram estabelecidos, uma série de tecnologias foram desenvolvidas tendo o uso do ozônio como principal fonte, porém, apesar de ter uma eficácia amplamente conhecida e validada, ainda existem áreas pouco estudadas, criando um atraso na inovação tecnológica no que diz respeito ao ozônio.

Desde o início de sua descoberta, o ozônio se destacou por seus benefícios desinfetantes, sendo um elemento nobre tanto com o meio ambiente quanto com os tecidos com os quais entra em contato, tendo, alta ação bactericida, sem ter as reações desfavoráveis que o cloro tem, por exemplo, e ambos tendo eficácia semelhante contra bactérias.

Diante do exposto, é imprescindível aproveitar o grande potencial terapêutico do ozônio em áreas que estão sendo 
redesenhadas para uma adaptação mais ecologicamente correta, tendo em vista a nova visão de mundo One Health. Uma área com grande potencial médico, produtiva e comercial é a utilização do ozônio na rotina da ordenha, que visa prevenir a mastite clínica, realizando a desinfecção antes e após a ordenha.

A aplicação preventiva de ozônio em vacas leiteiras já ganhou grande relevância há algum tempo, um dos tratamentos preventivos mais utilizados é a prevenção de metrite em vacas no pós-parto, em que as aplicações de ozônio são feitas por via intrauterina em diferentes doses pós-parto.

Um estudo realizado por Djuricic, et al., 2011, mostra muito bem o potencial que o ozônio tem em termos de tratamentos preventivos, neste estudo a aplicação preventiva do ozônio intrauterino teve diferentes efeitos no desempenho reprodutivo em vacas leiteiras.

Vacas tratadas com ozônio 24-48 h após o parto em comparação com vacas controle não tratadas: elas engravidaram mais cedo (110,5 dias ou 105 dias versus 112 dias, respectivamente), tiveram uma melhor taxa de concepção no primeiro serviço e a taxa de concepção para todos os serviços também melhorado.

Agora, voltando ao que é a mastite, para o tratamento preventivo atualmente existem principalmente pré-dipping e dippings, geralmente à base de iodo e clorexidina, e são esses compostos básicos que lideram a indústria de produtos de ordenha de rotina.

Esses compostos nos fornecem uma diretriz para podermos estabelecer e justificar o uso do ozônio em uma rotina habitual de ordenha já estabelecida, pois se um composto base é a clorexidina, esta pode ser substituída por compostos ozonizados, conforme mostra um estudo, no que comparou-se o efeito da clorexidina contra o ozônio no tratamento da inflamação gengival em pacientes ortodônticos submetidos a tratamentos de rotina, este estudo concluiu que o uso da irrigação subgengival de soluções ozonizadas é eficaz para tratar e reduzir a inflamação gengival em pacientes com processos ortodônticos (Sandra, et al., 2019).

Isso demonstra a semelhança dos dois compostos em seus efeitos antibacterianos de forma preventiva e, embora seja verdade que atualmente existam produtos de ordenha à base de ozônio de rotina, eles não são muitos ou tão divulgados quanto deveriam ser, considerando sua grande terapêutica conjunta e benefício ambiental. É aqui que se pretende estimular o despertar científico para a realização de pesquisas e validar a sua utilização justificando-se através de dados credíveis e técnicos que apóiem a sua utilização em áreas subdesenvolvidas como a laticínios.

\section{Ozonioterapia e One Health}

Um termo que nos últimos anos teve um boom incrível dada a sua importância, é o termo One Health, ou saúde única, termo que possui diferentes perspectivas e interpretações, devido à interação dos diversos fatores que estão envolvidos, desde fatores epidemiológicos, patologia, insegurança alimentar, mudanças demográficas humanas, a evolução dos sistemas de produção animal e mudanças climáticas.

Atualmente a nível global existe uma maior consciência da necessidade de abordar os problemas de saúde de forma abrangente, reorientando a gestão da saúde de uma forma mais envolvente, tendo em conta a saúde humana, a saúde animal e a saúde do ecossistema. Esta nova abordagem tem sido incentivada pelas diferentes doenças geradas nas últimas décadas, doenças que sendo zoonoses, deve-se levar em consideração que são bidirecionais, tanto zoonose quanto antropozoonose, o que por sua vez contribui para uma resistência antimicrobiana generalizada em humanos como em animais.

Todos esses fatores contribuem para o que é percebido como uma crise na capacidade de gestão global da saúde e cria uma demanda por novos mecanismos para enfrentar as ameaças à saúde, de forma integrada e transdisciplinar, ou seja, abordando as ameaças à saúde desde suas origens, e na interface saúde do ecossistema - saúde animal - saúde humana.

Dito isso, é possível perceber a importância da abordagem One Health, que vai além do fator doença e zoonoses, é 
antes um paradigma em que a saúde é influenciada por uma série de mecanismos interdependentes.

Essa interdependência é muito bem exemplificada por Evans, et al, (2014) que propõem a sigla HEALTH da seguinte forma (de acordo com a sigla em inglês):

- Humanos, (Humans)

- Ecossistemas (Ecosystems)

- Animais, (Animals)

- Viver, (Living)

- Juntos, (Together)

- Harmoniosamente. (Harmoniously)

Nesse quadro único de saúde, a relevância do veterinário é enorme, pois faz parte de poder gerar disseminação e melhor manejo por fazer parte dos profissionais que atuam no controle de grande parte do ecossistema, seja a partir do nível de saúde, produção, biologia, estudo de ecossistemas, epidemiologia, etc., visto que atuar em conjunto com outros profissionais da saúde humana e ecossistêmica pode gerar uma melhor contribuição para a melhoria da saúde global e interdisciplinar. (Videla, et al, 2014)

Um dos fatores que mais vem sendo mencionado em termos de enfoque One Health é a detecção de alta resistência antimicrobiana, gerada pelo uso crescente de antibióticos de forma descontrolada na pecuária (Figura 1), sendo a indústria de laticínios uma das áreas que apresenta mais uso de antibióticos em sua cadeia produtiva, que deve ser controlada uma vez que apenas a pecuária representa 40\% da renda agrícola gerada mundialmente (Acar, et al., 2013; Nabarro, et al., 2014)

Figura 1. Representação conceitual do possível movimento de cepas / genes bacterianos resistentes a antibióticos entre diferentes ecossistemas.

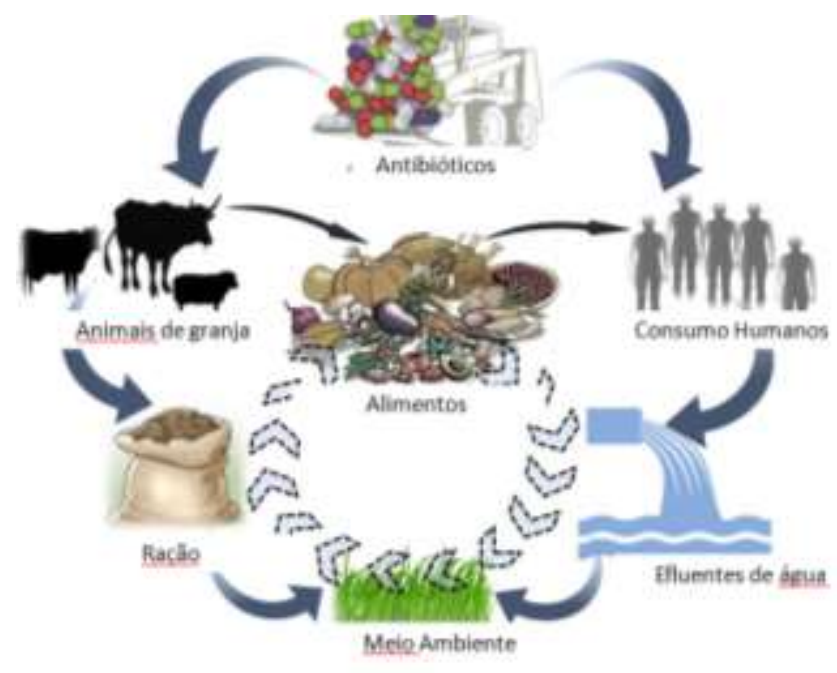

Fonte: Adaptado de Sharma, et al., (2018).

A implementação de boas práticas de higiene nas fazendas leiteiras é um pré-requisito para a produção de produtos de alta qualidade e leite cru microbiologicamente seguro. Uma vez que o ozônio é um poderoso agente oxidante ativo contra uma ampla gama de microrganismos, incluindo vírus, bactérias, leveduras, bolores e protozoários, o tratamento com ozônio pode ser aplicado em fazendas de leite como uma alternativa para erradicar o uso indiscriminado de antibióticos em fazendas de leite. (Varga, et al., 2016; Nascente, et al., 2019).

Nas últimas décadas, o uso do ozônio se estabeleceu em diferentes áreas, sendo a indústria de laticínios uma das mais novas em sua aplicação, tendo em vista a redução do uso de antibióticos. 
Diferentes estudos em todo o mundo têm sido realizados demonstrando sua eficácia na indústria de laticínios, Martínez, (2015) realizou um estudo em que duas concentrações de ozônio na forma gasosa foram utilizadas em vacas com mastite subclínica grau 3 e mastite clínica, os resultados obtidos foram favoráveis por ter redução na contagem bacteriana, sendo os tratamentos com ozônio eficientes e com custos mais baixos que os antibióticos convencionais, além de não apresentarem tempo de carência que influencia diretamente nos custos de produção por não haver pedidos de descarte de leite.

Pelaez (2015), realizou outro estudo com o ozônio na forma de gás, no qual os resultados mostraram que o tratamento com antibióticos teve um efeito curativo mais rápido do que com o ozônio (24 horas antes), mas elevou os custos dos tratamentos.

Entre as vantagens do tratamento com ozônio está a variedade de formas de aplicação que tem, por exemplo, Quintana, et al., (2019) relataram o caso de uma vaca com mastite subclínica tratada com óleo ozonizado, que apresentava infecção por Staphylococcus Aureus. A vaca foi tratada por 3 dias consecutivos com óleo de girassol ozonizado na quantidade de $10 \mathrm{ml}$ por quarto infectado, e um tratamento controle foi realizado com outra vaca com as mesmas características, que foi tratada com óleo de girassol na quantidade de $10 \mathrm{ml}$ por quarto. Ao final do experimento, foi realizada novamente cultura bacteriana e a vaca tratada com óleo de girassol ozonizado não apresentou crescimento bacteriano, e a vaca controle, tratada com óleo de girassol, ainda apresentou crescimento bacteriano, apresentando infecção por Staphylococcus Aureus.

É assim que o ozônio se apresenta como uma alternativa com grande potencial terapêutico para o tratamento da mastite, não colocando em risco a saúde humana ou animal, pois não gera resistência microbiana, além de ser de baixo custo e amigável ao ecossistema por não deixar desperdício.

\section{Considerações Finais}

Ao longo dos anos viu-se como a medicina veterinária dentro da pecuária evoluiu, para aumentar a eficácia dos tratamentos sem comprometer a produtividade das propriedades.

No caso da pecuária leiteira, os tratamentos seguem a premissa de serem tratamentos fortes e de ação rápida, com os quais são preferidos tratamentos em que menos aplicações de medicamentos são feitas, mas na mesma vez, que estes sejam suficientemente fortes para curar doenças rapidamente e assim evitar descartar o leite por muito tempo.

Com o uso de antibióticos cada vez mais potentes, aliado ao seu uso indiscriminado na pecuária leiteira, vem se gerando resistência microbiana, o que prejudica tanto os animais quanto o produtor, pois a cada vez aumentam os gastos com material médico devido a tratamentos malsucedidos, principalmente para mastite.

Nessa perspectiva, encontrar um método eficaz de tratamento da mastite que ajude a saúde animal beneficie economicamente o produtor e melhore a qualidade dos produtos finais que chegam ao consumidor é extremamente importante.

Conhecendo todos os benefícios do ozônio e sua eficácia em termos de tratamentos anteriores em outros tipos de produções e doenças, surge o interesse em avaliar sua eficácia na mastite, tanto clínica quanto subclínica. Esse interesse em gerar novas pesquisas que dêem origem a dados científicos confiáveis sobre seu uso ajudará a criar protocolos e mecanismos de tratamento eficazes, que por sua vez sejam compatíveis com a visão de redução do uso indiscriminado de antibióticos, aliada à obtenção de produtos de melhor qualidade para consumo humano, resultando assim numa melhoria da saúde humana ao salvaguardar a saúde animal.

Por este motivo, sugere-se a realização de futuros estudos que avaliarem especificamente o tratamento da mastite em vacas leiteiras com ozônio, a partir de sua metodologia de utilização dentro da rotina de ordenha, bem como diferentes dosagens e formas de aplicação do ozônio, a fim de gerar dados científicos atuais e fortalecer com dados gerados por pesquisas, os dados bibliográficos de que dispomos. 


\section{Referências}

Acar, J. F., \& Moulin, G. (2013). Integrating animal health surveillance and food safety: the issue of antimicrobial resistance. Rev. sci. tech. Off. int. Epiz, 32 (2), 383-392.

Arichivala, N., \& Argudo, D. (2012). El empleo de la ozonoterapia en ganadería de leche como alternativa de tratamiento para la mastitis clínica. Tese (Pregrado)- Facultad De Ciencias Agropecuarias. Escuela De Medicina Veterinaria Y Zootecnia. Universidad De Cuenca. Ecuador.

Beltran, J., Torregrosa, J., Dominguez, J., \& García, J. (2001). Depuracion de las aguas de lavado de aceitunas negras mediante procesos biologicos aerobios y de ozonizacion. Revista Grasas y Aceites. España. ISSN: 0017-3495. 52. Fasc. 3-4.

Bocci, V., Luzzi, E., Corradeschi, F., Paulesu, L., Rossi, R., Cardaioli, E., \& Di Simplicio, P. (1993). Studies on the biological effects of ozone: 4. Cytokine production and glutathione levels in human erythrocytes. J Biol Regul Homeost Agents. Oct-Dec;7(4):133-8.

Calderón, A., Arteaga, M., Rodríguez, V., Arrieta, G., Bermúdez, D., \& Villareal, V. (2011). Efecto De La Mastitis Subclínica Sobre El Rendimiento En La Fabricación Del Queso Costeño. Biosalud [online]. Córdoba, Colombia, 10(2), 16-27.

Campos, A., \& Calles, B. (2003). La ozonoterapia, una opción de tratamiento en la medicina veterinaria. Tese (Pregrado) Centro de Investigaciones del Ozono. Universidad de Granma. Cuba. 2003

Carrijo, M., \& García, C. (2006). Eficácia da ozonioterapia no tratamento de mastite subclínica de vacas em lactacao. Veterinaria Noticias. Uberlándia Brazil. 109-115.

Djuricic, D., Vince, S., Ablondi, M., Dobranic, T., \& Samardzija, M. (2011). Effect of Preventive Intrauterine Ozone Application on Reproductive Efficiency in Holstein Cows. Reproduction in Domestic Animals, 47(1), 87-91. 10.1111/j.1439-0531.2011.01805.x

Evans, B. R., \& Leighton, F. A. (2014). A history of One Health. Rev. sci. tech. Off. int. Epiz. 33 (2), 413-420.

Food and Agriculture Organization. (2010). Aumenta consumo y producción de productos pecuarios en América Latina y el Caribe.

Frisón, L., Vissani, M., Ocampo, H., Ponisio, D., \& Basílico, J. (2013). Effects of ozonated water on pathogens and spoilage microorganisms of fruits and vegetables. Revista Venezolana de Ciencia y Tecnología de Alimentos. Venezuela. 4 (1): 119-131.

Glaze, W. H. (1987). Drinking-water treatment with ozone. Environmental Science \& Technology. 21(3), 224-230. 10.1021/es00157a001

Góchez, D., Raicek, M., Pinto Ferreira. J., Jeannin, M., Moulin, G., \& Erlacher-Vindel, E. (2019). OIE Annual Reporton Antimicrobial Agents Intended for Use in Animals: MethodsUsed. Front. Vet. Sci. Paris, Francia. 6:317. 10.3389/fvets.2019.00317

Guimarães, J. L. B., Paiva Brito, M. A. V., Lange, C. C., Silva, M. R., Ribeiro, J. B., Mendonca, L. C., Mendonça, J. F. M., \& Souza, G. N. (2017). Estimate of the economic impact of mastitis: A case study in a Holstein dairy herd under tropical conditions. Journal of mammary gland biology and neoplasia. Netherlands. V23, P27-41. 10.1016/j.prevetmed.2017.04.011

Hamann, J., \& Stanitzke U. (1990). Studies on pathogenesis of bovine mastitis by comparison of milking conditions as calf suckling, hand milking and machine milking: reactions of the teat tissue. Milchwissenschaft. 45(10):632-637.

Harmon, R. J. (1994). Physiology of mastitis and factors affecting somatic cell counts. J. Dairy Sci. 77: 2103-2112. 10.3168/jds.S0022-0302(94)77153-8

Hughes, K., \& Watson, C.J. (2018). The Mammary Microenvironment in Mastitis in Humans, Dairy Ruminants, Rabbits and Rodents: A One Health Focus. Journal of mammary gland biology and neoplasia. New York, U.U.E.E. V.23, P.27-41. 10.1007/s 10911-018-9395-1

Jones, G. M., Pearson, R. E., Clabaugh, G. A., \& Heald, C. W. (1984). Relationships between somatic cell counts and milk production. J Dairy Sci. Aug;67(8):1823-31. 10.3168/jds.S0022-0302(84)81510-6. PMID: 6480964.

Kitchen, B. J. (1981). Review of the progress of dairy science: Bovine mastitis: Milk compositional changes and related diagnostic tests. J Dairy Sci., 64: 167188. $10.1017 / \mathrm{s} 0022029900021580$

Kleinschroth, E., Rabold, K., \& Deneke, J. (1991). La Mastitis. España. EDIMED. Salingraf. S. A. L. 7-18.

Martinez, P. E. (2015). Evaluación De Dos Dosis De Ozono En El Tratamiento De Mastitis Bovina. Tese (Graduacao)- Facultad De Medicina Veterinaria Y Zootecnia, Universidad Central Del Ecuador, Quito, Ecuador.

Morais, J. P., Tim, C. R., \& Assis, L. (2020). Considerations about the use of Ozone therapy (O3) in the treatment of Endometriosis. Research, Society and Development, 9(9), e403997616. https://doi.org/10.33448/rsd-v9i9.7616

Mustafa, M. G. (1998). Biochemical basis of ozone toxicity. Free Radic Biol Med; 9(3): 245-65. 10.1016/0891-5849(90)90035-H

Nabarro, D., \& Wannous, C. (2014). The potential contribution of livestock to food and nutrition security: the application of the One Health approach in livestock policy and practice. Rev. sci. tech. Off. int. Epiz, 33 (2), 475-485.

Nascente, E., Chagas, S. R., Pessoa, A. V. C., Matos, M. P. C., Andrade, M. A., \& Pascoal, L. M. (2019). Potencial antimicrobiano do ozônio: aplicações e perspectivas em medicina veterinária. PUBVET. Goiânia, Brasil. 13(9), a412, 1-14, Set., 10.31533/pubvet.v13n9a412.1-14

Ogata, A., \& Nagahat, J. (2000). Intramammary Application of Ozone Therapy to Acute Clinical Mastitis in Diary Cows. Theriogenology. Japan. 681-686.

Özlem, S., Sabuncu, A., Baaran, B., Koçak, Ö., Yldar, E., \& Güzel, Ö. (2015). Comparison of Intramammary Ozone Administration Doses in Dairy Cows with Clinical Mastitis. Acta Scientiae Veterinariae, Porto Alegre, Brasil. 43, 1-7. 
Peláez, H. O. (2015). Uso De Ozonoterapia Para El Tratamiento De Mastitis Subclinica En Bovinos. Tese (Magíster En Sistemas Sostenibles De Producción Animal)- Sistema de Postgrado, Universidad Catolica de Santiago de Guayaquil, Guayaquil, Ecuador.

Pereira, A. S., Shitsuka, D. M., Parreira, F. J., \& Shitsuka, R., (2018). Metodologia Da Pesquisa Científica. UFSM. <https://repositorio.ufsm.br/bitstream/h andle/1/15824/Lic_Computacao_Metodologia-Pesquisa-Cientifica.pdf?sequence=1>

Philpot, W., \& Nickerson, S. (2002). Vencendo a Luta Contra a Mastite. Publicado por Westfalia Surge Inc. e Westfalia Landtechnik do Brasil Ltda. Brasil. Milkbizz. Edição Brasileira. 6-9, 15-17, 22-27, 38-43.

Pitkälä, A., Haveri, M., Pyörälä, S., Myllys, V., \& Honkanen-Buzalski, T. (2004). Bovine mastitis in finland 2001- Prevalence, distribution of bacteria, and antimicrobial resistance. J Dairy.Sci, 87, 2433-2441. 10.3168/jds.S0022-0302(04)73366-4

Quintana, M. C. F., Domingues, I. M., \& Ribeiro, A. R. (2019). Uso de óleo ozonizado no tratamento de mastite subclínica em vaca Jersey: Relato de caso. PUBVET. Minas Gerais, Brasil. 13(5), a336, 1-4. 10.31533/pubvet.v13n5a336.1-4

Radinović, M., Davidov, I., Kovačević, Z., Stojanović, D., Galfi, A., \& Erdeljan, M. (2019). Basic Principles Of Mastitis Therapy. National and University Library of the Republic of Srpska. Serbia. 19(1). 10.7251/vetjen1901110r

Ramírez, J. E. G., González, R. E. V., Lorenzo, E. V., \& Trujillo, A. M. (2012). Morphophysiology of papaya seedling irrigated with three different qualities of water. Centro Agrícola, 39(4): 31-37, CE: 24,12 CF: cag074121880.

Ricaurte, S. (2006). Ozonoterapia, una opción para el sector agropecuario. Revista electrónica de veterinaria redvet. España. 7(10).

Sampimon, O. C., Lam, T. J., Mevius, D. J., Schukken, Y. H., \& Zadoks, R. N. (2011). Antimicrobial susceptibility of coagulasenegative staphylococci isolated from bovine milk samples. Vet Microbiol. 150:173 - 179. 10.1016/j.vetmic.2011.01.017

Sandra, V. K. V., Nagireddy, R. R., Nooney, A., \& Nadhamuni, M. (2019). Comparison of efficiency of ozone and chlorhexidine subgingival irrigation in orthodontic patients for controlling gingival inflammation. Research. India. 74(2) 82 - 86. 10.17159/2519-0105/2019/v74no2a5

Schukken, Y. H., Wilson, D. H., Welcome, F., Garrison-Tikofsky, L. \& Gonzales, R. N. (2003). Monitoring udder health and milk quality using somatic cell counts. Veterinary Research. 34(5): 579-596. 10.1051/vetres:2003028

Sharma, C., Rokana, N., Chandra M., Singh, B. P., Gulhane, R. D., Gill, J. P. S., Ray, P., Puniya, A. K., \& Panwar, H. (2018). Antimi crobial Resistance: Its Surveillance, Impact, and Alternative Management Strategies in Dairy Animals. Front. Vet. Sci. Chandigarh, India. 4(237). 10.3389/fvets.2017.00237

Sharma, N. (2007). Alternative approach to control intramammary infection in dairy cows- Review. Asian J. Anim. Vet. Adv. India. 2(2): 50-62. 10.3923/ajava.2007.50.62

Sharma, N., Singh, N. K. \& Bhadwal, M. S. (2011). Relationship of somatic cell count and mastitis: An overview. Asian Aust. J. Anim. Sci., India. 24(3): 429438.

Sunnen, G. (2003). Ozone in medicine: overview and future directions. Journal of Advancement in Medicine. New York. E.E.U.U. 1(3), 159-174. Corpus ID: 30587821

Swinkels, J. M., Hogeveen, H., \& Zadoks, R. N. (2005). A partial budget model toestimate economic benefits of lactational treatment of subclinical Staphylococcisaureus mastitis. J Dairy.Sci, 88, 4273-4287. 10.3168/jds.S0022-0302(05)73113-1.

Varga, L., \& Szigeti, J. (2016). Use of ozone in the dairy industry: A review. International Journal of Dairy Technology. Mosonmagyaróvár, Hungary. 69(2). $10.1111 / 1471-0307.12302$

Vidal, L., Zamora, Z., \& Urruchi, W. (2009). Utilidad potencial de la ozonoterapia en la Medicina Veterinaria. Revista electrónica de veterinaria. Brasil.

Videla, O. E., \& Urzua, J. O. (2014). Beneficios de la incorporación del concepto «Una sola salud» a la organización de los Servicios Veterinarios nacionales. Rev. sci. tech. Off. int. Epiz., 33 (2), 393-399.

Zadoks, R. N., Allore, H. G., Barkema, H. W., Sampimon, O. C., Grohn, Y. T., \& Schukken, Y. H. (2001). Analysis of an outbreak of Streptococcus uberis mastitis. J Dairy.Sci, 84, 590-599.

Zorrilla, D. (2001). Cálculo teórico de propiedades moleculares mediante bases no estándar. Tese Doutorado. Universidad de Cadiz. España. 